\title{
The Relationship BETWEen LeAdERSHIP STYLES, InNovation and Organisational Performance: A Systematic Review
}

\author{
Tebogo Sethibe and Renier Steyn \\ School for Business Leadership, University of South Africa \\ Accepted: January 2015
}

\begin{abstract}
This paper is an attempt to consolidate the published scientific knowledge about the impact of leadership styles on the relationship between innovation and organisational performance. Concepts, statements and conceptual frameworks were used as structure to analyse the body of scientific knowledge. After consulting 31 major research databases using the systematic literature review methodology, only seven journals articles that examined the link between leadership, innovation and organisational performance were identified. The synthesis of the journal articles revealed (a) that consensus exists among researchers as far as the relevant concepts are concerned; (b) that most agree on the definition of leadership and innovation but that a uniform understanding of what constitutes organisational performance is lacking; and (c) that conceptual models are too simplistic and do not consider mediator variables or multiple financial criteria measures. The findings further reveal that innovation is significantly and positively related to superior organisational performance, and that, although transformational leadership style is significantly and positively related to innovation, transactional leadership style is more appropriate when the aim is to instil a culture of innovation. Transformational leadership style, by contrast, is mostly associated with organisational performance. In addition, the findings further reveal that none of the studies investigate the mediating effect of the nature of innovation (incremental and radical) on the relationship between leadership and organisational performance, and that none of the studies use the objective measures of financial performance such as ROA, ROE, price/earnings (P/E) and Tobin's $Q$ calculated from annual financial reports.
\end{abstract}

Key words: transformational leadership, transactional leadership, organisational innovation, organisational performance, systematic review

JEL: O31

\section{$1 \quad$ Introduction}

Innovation is broadly seen as an essential component for competitiveness and survival, embedded in organisational structures, processes, products, and services within the organisation (Gunday, Ulusoy, Kilic \& Alpkan, 2011). As a result, innovation is considered by many scholars as one of the most important determinants of firm performance (Adegoke, Walumbwa \& Myers, 2012; Durán-Vázquez, Lorenzo-Valdés \& Moreno-Quezada, 2012; Grant, 2012). According to GarcíaMorales, Matías-Reche and Hurtado-Torres (2008), leadership style has been recognised as one of the most important factors influencing the relationship between innovation and organisational performance, because leaders have the authority to set specific goals and encourage innovative initiatives from subordinates.

There is no shortage of documented studies in the literature that investigate the relationship between leadership and innovation. The general consensus among scholars is that transformational leadership style is significantly and positively related to organisational creativity and innovation (Al-Husseini \& Elbeltagi, 2012; Hu, Gu \& Chen, 2012; Tipu, Ryan \& Fantazy, 2012). On the other hand, several studies (Adegoke et al., 2012; Nybakk \& Jenssen, 2012; Durán-Vázquez et al., 2012) show that innovation is positively related to superior financial performance. Although some studies show no relationship (Selby, 2010; Lööf \& Heshmati, 2006; Kandybin \& Kihn, 2004), others show mixed results with non-innovative firms outperforming innovators in some instances (Martin, 2012; Forsman \& Temel, 2011; Kannebley, Sekkel \& Araújo, 2008). 
However, despite this overwhelming empirical evidence showing the link between leadership style and innovation on the one hand and innovation and financial performance on the other, very few studies have been designed to trace systematically the causal path of the effect of innovation on financial performance by examining the influence of leadership style. Therefore, the purpose of this paper is to review systematically the state of research on the relationship of these strategic variables, namely, leadership style, innovation and organisational performance.

\section{Literature review}

A systematic review is a process for reviewing relevant literature using a comprehensive, preplanned strategy to locate existing literature, evaluate its contribution, analyse and synthesise findings and report on evidence to allow conclusions to be reached about what is known and what is not (Denyer \& Tranfield, 2009). Originating in the medical sciences, a systematic review differs from conversional reviews in that it aims at synthesising research in a systematic, transparent and reproducible manner (Tranfield, Denyer \& Smart, 2003). According to Robson Clarke, Cullen, Bielecky, Severin, Bigelow, Irvin, Culyer and Mahood (2007), a systematic literature review uses explicit, thorough methods to identify, select, appraise and synthesise a set of research studies on a well-defined topic.

In management research, a literature review process is a key tool used to manage the diversity of knowledge for a specific enquiry (Robson et al., 2007). Thus, the primary purpose of a literature review is: (1) to identify knowledge gaps and develop a research problem; (2) to identify the appropriate theoretical framework, issues and variables related to a particular research topic; and (3) to find conceptual and operational definitions and the appropriate methodologies for investigation (Kaniki, 2009).

On the other hand, theory building is an essential process in the development of new knowledge (Morrison, 2003). Conceptually, knowledge can be seen as the result of three courses of action; namely, the creation of new theories; the expansion of existing theory; and the disconfirmation of theories that do not survive empirical scrutiny (Handfield \& Melnyk, 1998). Therefore, knowledge is not simply a matter of content, but the capacity of content to bring about effective actions (Morrison, 2003).

Perhaps it is in this context that Reynolds (1971) posits that a scientific body of knowledge consists of concepts and statements that scientists consider to be useful for achieving the purposes of science. Advancing the same argument and building on the seminal work of Mouton (1996) and Kerlinger and Lee (2000), De Vos, Strydom, Fouché and Delport (2011) present the three building blocks of science, namely; concepts, statements and conceptual frameworks.

- The Oxford Dictionary defines the term "concept" as "an idea or principle that is connected with the abstract" (Hornby, 2000:234). A more generalised definition put forward by Omar and Leite (1998:3) is a "specific classification based in common attributes of objects, people, events, phenomena, instances or specific ideas". Concepts act as the carriers of meaning; in other words, they enable researchers to identify and refer to a social phenomenon and as such, one could argue that concepts are the symbolic constructions by means of which people make sense of the attributive meaning of their words (Mouton, 1996). Thus, possession, understanding and use of concepts by researchers are the most basic requirements of scientific enquiry (De Vos et al., 2011).

- Statements, on the other hand, include definitions, hypotheses and propositions (De Vos et al., 2011). According to Mouton (1996) a definition is a statement that delimits or demarcates the meaning of a word in terms of its sense of reference. However, it is worth mentioning that there are two distinctive types of definitions; namely, theoretical (connotative) and operational (denotative) definitions. A theoretical definition refers to the specification of the meaning of the connotative meaning of a concept, whereas an operational definition describes certain operations, usually some type of measurement, under which the use of the concept is valid. 
Along the same lines, a hypothesis is an expectation about the nature of things derived from theory and is a statement of something that should be observed in the real world if the theory is correct (De Vos et al., 2011). As a result, an empirical hypothesis is an information item that becomes transformed into new observations via interpretation of the hypothesis into observables, instrumentation, scaling and sampling (Handfield \& Melnyk, 1998). The observable units in this context refer to variables (entities which are capable of assuming two or more values) which can be operationalised empirically by measurements (Bacharach, 1989).

In contrast, a proposition is a statement which contains testable claims (Mouton, 1996). At an abstract level, a proposition states the relationship between constructs (Bacharach, 1989). The primary difference between propositions and hypotheses is that propositions involve concepts, whereas hypotheses require measures (Whetten, 1989). In other words, although propositions and hypotheses are merely statements of relationships, propositions are the more abstract and encompassing of the two. Propositions relate the more abstract constructs to one another, whereas hypotheses are more concrete operational statements built from specific variables (Bacharach, 1989).

- Conceptual framework typically includes typologies, models, theories and paradigms (De Vos et al., 2011). According to Mouton (1996), typology can be defined as a conceptual framework in which phenomena are classified in terms of characteristics that they have in common with other phenomena. Capecchi (1968) defines typology, in its simplest form, as a selection of a certain number of combinations of groups of variables. This selection may be based on the data afforded by empirical research. Thus, a typology presents a static image or cross-section of a specific class of events (Mouton, 1996).

Conversely, a model is defined as a representation of reality (De Vos et al., 2011). In an attempt to simplify the term "model", Whetten (1989) presents an interesting analogy by suggesting that if we think of theory as a story about why, then a model can be properly viewed as a visual aid that helps storytellers highlight the main features of their explanations. However, it is worth mentioning that a model does not necessarily equate to theory. According to Kerlinger and Lee (2000), a theory is a set of interrelated constructs (concepts), definitions and propositions that present a systematic review of the phenomena by specifying relations about the variables, with the purpose of explaining and predicting a phenomenon. As Bacharach (1989) points out, the primary purpose of theory (theoretical statements) is to organise "parsimoniously" and to communicate "clearly".

When the researcher embarks on a process of organising and communicating or explaining unknown phenomena, the research paradigm plays an important role. According to De Vos et al. (2011), a paradigm is a general framework for looking at life, and as such, influencing how the researcher views and interprets material about reality and guiding the consequent action to be taken. Therefore, this paper will follow the three building blocks of science (concepts, statements and conceptual framework) to review the state of research that investigates the relationship between leadership style, innovation and organisational performance.

\section{Methodology}

While systematic reviews are designed to reduce bias, a full operational protocol should be written to define and guide the search process (White \& Schmidt, 2005). Hence, the systematic review methodology has been developed to minimise the effect of selection, publication and data extraction bias (Nightingale, 2009). According to Nightingale (2009) the methodology of the systematic literature review should clearly state the aims and objectives of the review, the inclusion and exclusion criteria for studies, the way studies are identified, and the plan of the analysis. In this way, the systematic review helps to develop a reliable knowledge base by accumulating knowledge from a range of studies (Tranfield et al., 2003). Given this purpose, clear guidelines should determine which research should be included and excluded in the final analysis 
(Green, Johnson \& Adams, 2006). Moreover, it is worth noting that the decision pertaining to inclusion and exclusion remains relatively subjective. Thus, to increase reliability, it is recommended that this stage of the systematic review should be conducted by more than one reviewer (Tranfield et al., 2003).

To enhance the reliability of the present research, two researchers (the author and co-author) were involved in the literature search. The primary aim of this systematic review was to analyse prior studies that investigate the relationship between leadership, innovation and organisational performance, and to identify emergent themes based on the building blocks of science presented in the literature review. The keywords "leadership" (leaders*), "innovation" (innov*) and "performance" (perform*) were used in the search. As the keywords "creativity" (creative*) and innovation are occasionally used interchangeably in the literature, these were also included. Similarly, the keywords "financial" (financ*), "output" (outp*), and "return on investment" (return*) were used because they are occasionally used interchangeably with "performance". The options (criteria) selected for the search were full text, peer-reviewed and scholarly journals. Target articles needed to include all three keywords in a title.

With no time limit set, 21 databases (Africa-Wide Information, Business Source Complete, CAB Abstracts, Communication \& Mass Media Complete, Communication Abstracts, eBook Collection (EBSCOhost), EconLit with Full Text, Education Source, ERIC, Humanities \& Social Sciences Index Retrospective: 1907-1984 (H.W. Wilson), Humanities Source, Library \& Information Science Source, Library, Information Science \& Technology Abstracts, MasterFILE Premier, PsycARTICLES, PsycBOOKS, PsycCRITIQUES, PsycEXTRA, PsycINFO, Regional Business News, Social Work Abstracts, SocINDEX) were searched on EBSCOhost and 13 articles were retrieved.

Again no time limit was set on a search of ten databases (Applied Social Sciences Index and Abstracts (ASSIA) (1987 - current) information, COS Scholar Universe information, ebrary® ebooks information, ERIC (1966 - current) information, Library and Information Science Abstracts (LISA) (1969 - current) information, PAIS International (1914 - current) information, ProQuest Business Collection (1951 - current) information, ProQuest Central (1971 - current) information, Social Services Abstracts (1979 - current) information, Sociological Abstracts (1952 - current) information) on ProQuest, which resulted in ten articles being retrieved. In total 23 articles were retrieved from both EBSCOhost and ProQuest. However, six duplicate articles were identified, resulting in 17 distinct articles retrieved from the search.

The abstracts of the articles which met the first level of inclusion criteria were analysed in order to identify those articles that (1) use financial performance as a measure of organisational performance; (2) are published in English; and (3) treat leadership style, innovation and performance as variables. Seven articles (presented in Table 1) met these criteria.

\section{$4 \quad$ Findings}

From Table 1 it is clear that only seven articles retrieved investigate the relationship between leadership styles, innovation and organisational performance. These findings illustrate that there is a lack of research that investigates the link between leadership, innovation and corporate performance. However there is no shortage of studies that investigate the relationship between these strategic variables. When the keywords "leadership" (leader*) and "innovation" (innov*) were used, 377 articles from EBSCOhost and 161 articles from ProQuest were retrieved. Similarly, when the keywords "innovation" (innov*), and "performance" (perform*) were used in the search strategy, 843 articles were retrieved from EBSCOhost and 361 articles from ProQuest.

From the obtained sample of seven articles, five articles focus specifically on transformational leadership style, whereas two articles investigate both transformational and transactional leadership styles. Of the seven articles, one is more than ten years old, while the others were published in the last eight years. The seven articles that explicitly investigate the relationship between leadership style, innovation and organisational performance were analysed according to 
the three building blocks of science (concepts, statements and conceptual frameworks) identified by De Vos et al. (2011).

Table 1

Articles that investigate leadership styles, innovation and organisational performance

\begin{tabular}{|c|c|c|c|c|}
\hline Article & Year & Author (s) & Title & Journal \\
\hline 1 & 1993 & Howell \& Avolio & $\begin{array}{l}\text { Transformational leadership, transactional leadership, } \\
\text { locus of control and support for innovation: key } \\
\text { predictors of consolidated-business-unit performance }\end{array}$ & $\begin{array}{l}\text { Journal of Applied } \\
\text { Psychology }\end{array}$ \\
\hline 2 & 2008 & $\begin{array}{l}\text { García-Morales, } \\
\text { Lloréns-Montes \& } \\
\text { Verdú-Jover }\end{array}$ & $\begin{array}{l}\text { The effects of transformational } \\
\text { leadership on organizational performance through } \\
\text { knowledge and innovation }\end{array}$ & $\begin{array}{l}\text { British Journal of } \\
\text { Management }\end{array}$ \\
\hline 3 & 2008 & $\begin{array}{l}\text { Garcia-Morales, } \\
\text { Matías-Reche \& } \\
\text { Hurtado-Torres }\end{array}$ & $\begin{array}{l}\text { Influence of transformational leadership on } \\
\text { organizational innovation and performance depending } \\
\text { on the level of organizational learning in the } \\
\text { pharmaceutical sector }\end{array}$ & $\begin{array}{l}\text { Journal of } \\
\text { Organizational Change } \\
\text { Management }\end{array}$ \\
\hline 4 & 2008 & $\begin{array}{l}\text { Matzler, Kepler, } \\
\text { Deutinger \& Harms }\end{array}$ & $\begin{array}{l}\text { The relationship between transformational leadership, } \\
\text { product innovation and performance in SMEs }\end{array}$ & $\begin{array}{l}\text { Journal of Small } \\
\text { Business and } \\
\text { Entrepreneurship }\end{array}$ \\
\hline 5 & 2013 & $\begin{array}{l}\text { Overstreet, Hanna, } \\
\text { Byrd, Cegielski \& } \\
\text { Hazen }\end{array}$ & $\begin{array}{l}\text { Leadership style and organizational innovativeness } \\
\text { drive motor carriers toward sustained performance }\end{array}$ & $\begin{array}{l}\text { The International } \\
\text { Journal of Logistics } \\
\text { Management }\end{array}$ \\
\hline 6 & 2013 & $\begin{array}{l}\text { Noruzy, Dalfard, } \\
\text { Azhdari, Nazari- } \\
\text { Shirkouhi \& } \\
\text { Rezazadeh }\end{array}$ & $\begin{array}{l}\text { Relations between transformational leadership, } \\
\text { organizational } \\
\text { learning, knowledge management, organizational } \\
\text { innovation, and organizational performance: an } \\
\text { empirical investigation of manufacturing firms }\end{array}$ & $\begin{array}{l}\text { International Journal of } \\
\text { Advanced Technology }\end{array}$ \\
\hline 7 & 2013 & Golla \& Johnson & $\begin{array}{l}\text { The relationship between transformational and } \\
\text { transactional leadership styles and innovation } \\
\text { commitment and output at commercial software } \\
\text { companies }\end{array}$ & $\begin{array}{l}\text { The Business Review, } \\
\text { Cambridge }\end{array}$ \\
\hline
\end{tabular}

\subsection{Concepts}

The words that appear in the keywords list are classified as concepts. However, only three of the seven articles list keywords. The most common keywords that appear in the three articles are "transformational leadership" and "organisational performance". Other keywords are "organisational learning", "knowledge management", "organisational innovation", "manufacturing firms", "pharmaceuticals industry", "innovation", "supply chain management”, "dynamic capabilities”, "organisational innovativeness", "transportation", "survey methods", and "structural equation modeling".

\subsection{Statements}

As stated in the literature review, statements include definitions, hypotheses and propositions.

\subsubsection{Definitions}

The most common words/terms and phrases defined are "transformational leadership", "innovation", "organisational innovation" and "organisational performance". Other definitions included in these articles are those of "knowledge slack", "leadership", "organisational innovativeness", "innovativeness", "innovation commitment", "innovation output", "innovation strategy alignment", "percentage of expenses allocated to innovation", "percentage of revenue allocated to innovation", "transactional leadership" and "theoretical framework". However, for the purpose of this paper, the focus is on the three variables under investigation; namely, leadership styles, innovation and organisational performance.

- Leadership styles: The articles mention transformational and transactional leadership styles. According to Howell and Avolio (1993) transformational leaders are leaders that focus their "efforts on long term goals, place value and emphasis on developing a vision and inspiring followers to pursue the vision, change or align systems to accommodate their vision rather than work within the existing systems, and coach followers to take a greater responsibility for 
their own development, as well as the development of others". Along similar lines, GarcíaMorales et al. (2008) define transformational leaders as leaders who can influence the fundamental attitudes and assumptions of an organisation's members by creating a common mentality to attain the firm's goal. Similarly, García-Morales et al. (2008) define transformational leadership as the style of leadership that heightens consciousness by the organisation's members of a collective interest and helps them to achieve it. More recently, Noruzy et al. (2013) define transformational leadership generically as a managerial style that seeks to inspire employees by charismatic speeches, motivation, and intellectual stimulation. In the same vein, Golla and Johnson (2013) define transformational leadership based on four components; namely, influence/charisma, inspiration, intellectual stimulation and individualised consideration. Only two articles investigate the influence of transactional leadership on the relationship between innovation and organisational performance. Howell and Avolio (1993) describe transactional leadership as a leadership style in which a leader-follower relationship is based on a series of exchanges or bargains between leaders and followers. Similarly, Golla and Johnson (2013) define transactional leadership as a style of leadership that focuses on individual self-interest and motivates individuals though rewards.

- Innovation: Only four of the seven articles define the terms "innovation" and "innovativeness". García-Morales et al. (2008) adopt the innovation definition formulated by the Product Development and Management Association (PDMA), which describes innovation as a new idea, method or device, or an act of creating a new product, service or process. Similarly, Golla and Johnson (2013) adopt the term "innovation" in relation to product and define product innovation as the market introduction of new goods or a significantly good service with respect to its capabilities, such as quality, user friendliness, software or subsystems. Conversely, Overstreet et al. (2013) opt for the term "innovativeness" rather than "innovation" and describe innovativeness as the propensity of an organisation to deviate from conventional industry practices by creating or adopting new products, processes or systems.

- Organisational performance: An interesting finding is that only one (Overstreet et al., 2013) of the seven articles that investigate the relationship between leadership, innovation and organisation performance attempts to define organisational performance. According to Overstreet et al. (2013) organisational performance can be measured using two distinct but related constructs; namely, operational and financial performance. According to them, operational performance refers to the firm's ability to efficiently and effectively provide services to the customer; whereas financial performance includes, among others, profitability and monetary measures such as return on investment, return on sales and operating ratios. Although other studies do not explicitly define organisational performance, attempts were made to show how organisational performance is measured. For instance, Golla and Johnson (2013) use the combination of innovation commitment and innovation output as a proxy for organisational performance. They calculate organisational performance as the difference between innovation output and innovation commitment. Innovation commitment is calculated as a percentage of expenses allocated towards innovation and innovation strategy, whereas innovation output is calculated as a percentage of revenue related to innovation and the number of new or enhanced products.

\subsubsection{Hypotheses, propositions and truth statements}

In the seven articles identified, a total of 54 hypotheses are postulated and tested. However, of the 54 hypotheses tested, only 26 investigate the link between leadership style, innovation and organisational performance. 11 hypotheses test the relationship between leadership style and organisational performance; nine hypotheses test the relationship between leadership style and organisational innovation, and six hypotheses test the relationship between organisational innovation and organisational performance. Other hypotheses test mediating effects such as locus of control, knowledge slack, absorptive capacity, organisational learning, tacitness, size and knowledge management on the relationship between leadership style, innovation and 
organisational performance.

No phrases resembling propositions were found. However, the tested hypotheses provide many truth statements. The results reveal overwhelming evidence that transformational leadership style is positively associated with innovation, and in turn, innovation is positively associated with organisational performance (García-Morales et al., 2008; García-Morales et al., 2008; Matzler et al., 2008; Overstreet et al., 2013; Noruzy et al., 2013). Of the 11 hypotheses which suggest a relationship between leadership style and organisational performance, nine hypotheses postulate a positive relationship between transformational leadership and organisational performance, and all hypotheses are supported by empirical findings. Of the 11 hypotheses that test the relationship between leadership style and organisational performance, two hypotheses postulate that there is a positive relationship between transactional leadership and organisational performance. Both these hypotheses were rejected, indicating that there is no relationship between transactional leadership and organisational performance. Eight hypotheses test whether a positive relationship exists between transformational leadership and organisational innovation or innovativeness, and the results reveal mixed results, with the overwhelming majority (seven) of the hypotheses supported, although one hypothesis test was rejected. Interestingly enough, the studies that show no relationship between transformational leadership and organisational innovation also reveal a statistically significant positive relationship between transactional leadership and organisational innovation (Golla \& Johnson, 2013). The six hypotheses that postulate a positive relationship between organisational innovation and organisational performance are supported by the data.

\subsection{Conceptual frameworks}

As described in the literature review, a conceptual framework consists of four building blocks; namely, theory, model, typology and paradigm. However, the seven articles analysed are quantitative in nature with no theoretical findings, and in turn no paradigms are discussed. However, several models were developed using various typologies/constructs; in particular, typologies related to organisational performance.

\subsubsection{Typologies}

As stated earlier, typologies can be defined as conceptual frameworks in which phenomena are classified. These are discussed with reference to the three key search terms.

- Leadership typologies: Two types of leadership styles, transformational and transactional, are investigated by two studies (Howell \& Avolio, 1993; Golla \& Johnson, 2013). The five other studies (García-Morales et al., 2008; García-Morales et al., 2008; Matzler et al., 2008; Overstreet et al., 2013; Noruzy et al., 2013) focus exclusively on the transformational style of leadership,

- Innovation typologies: None of the articles analysed investigate innovation in terms of typologies.

- Performance typologies: The two most popular typologies of organisational performance (operational and financial) are utilised in the seven articles analysed. Two articles (Howell \& Avolio, 1993; Noruzy et al., 2013) use operational performance, four articles (García-Morales et al., 2008; García-Morales et al., 2008; Matzler et al., 2008; Golla \& Johnson, 2013) use subjective financial performance, while one uses both operational and subjective financial performance measures (Overstreet et al., 2013). Interestingly enough, none of the articles analysed use objective measures (based on publicly reported annual financial reports) of financial performance.

\subsubsection{Model and theories}

Five of the seven articles analysed developed a model (García-Morales et al., 2008; GarcíaMorales et al., 2008; Noruzy et al., 2013; Overstreet et al., 2013; Matzler et al., 2008), whereas two studies (Golla \& Johnson, 2013; Howell \& Avolio, 1993) tested the hypotheses without integrating the results into a model. García-Morales et al. (2008) developed a model using eight 
constructs, namely, transformational leadership, knowledge slack, absorptive capacity, tacitness, organisational learning, performance, innovation and size. The model investigates the impact of transformational leadership on knowledge slack, absorptive capacity, tacitness, organisational learning and innovation. The model further investigates how tacitness, organisational learning and innovation influence organisational performance. Of significance to this study, the model demonstrates a positive relationship between transformational leadership, innovation and organisational performance.

Subsequently, García-Morales et al. (2008) developed another model using only three constructs; namely, transformational leadership style, organisational innovation and organisational performance. The model investigates how transformational leadership style can influence organisational innovation and organisational performance. Furthermore, the model examines the influence of organisational innovation and organisational performance. The results of the model show that transformational leadership style significantly and positively influences both innovation and organisational performance. In similar vein, the results of the model reveal that organisational innovation also positively influences organisational performance.

Along the same lines, Matzler et al. (2008) investigated the relationship between transformational leadership style, innovativeness, growth and profitability and also developed a model. Although the results reveal that transformational leadership style impacts positively on growth and profitability, the results of the model illustrate that transformational leadership style contributes more significantly to innovativeness. The results also show that innovativeness influences both growth and profitability.

More recently, Noruzy et al. (2013) developed a model using transformational leadership style, organisational learning, knowledge management, organisational innovation and organisational performance. Their study investigates the mediating effect of organisational learning and knowledge management on the relationship between transformational leadership style and organisational innovation. The authors further investigate how transformational leadership style, organisational innovation and organisational learning impact on organisational performance. In support of prior findings, the model shows that transformational leadership style positively influences organisational innovation and in turn, organisational innovation positively influences organisational performance.

Following a different strategy, Overstreet et al. (2013) developed a covariance-based structural equation model and tested the effect of transformational leadership style on organisational innovativeness and organisational performance (operational and financial). The results support both the direct and indirect effects of organisational innovativeness on the relationship between transformational leadership and organisational performance. It is interesting to note that organisational innovativeness contributes more to operational performance relative to financial performance. It is also worth mentioning that the model illustrates the impact of operational performance on financial performance.

In neither of the other two articles analysed were models developed, but the findings of these studies contribute to the body of knowledge. Contrary to studies in which models were developed, these studies investigate the effects of both transactional and transformational leadership styles on innovation and organisational performance. Furthermore, although Howell and Avolio (1993) did not develop a model, the results of their study validate the model developed by Bass (1985) in several ways. In the first instance, findings show that transformational leadership style directly and positively predicts organisations' unit level performance; and secondly, the results support the fact that innovation moderates the relationship between transformational leadership style and organisational performance. In contrast with previous findings, the results of the study by Golla and Johnson (2013) show a statistically significant relationship between transactional leadership and new product innovation, and a statistically significant relationship between transformational leadership style and revenue related to innovation. Interestingly, the results reveal no relationship between transformational leadership style and new product innovation, and no relationship between transactional leadership style and revenue related to innovation. 


\subsubsection{Paradigm}

None of the articles explicitly mention the paradigm adopted for those studies. However, it can reasonably be argued that the only paradigm that fits these studies is the positivist paradigm. According to Bryman (2004), positivism is an epistemological position that advocates the application of the methods of natural sciences to the study of social reality and beyond. The research methodologies for all articles analysed are deductive in nature and the hypothesis testing was conducted in the positivist manner.

\subsection{Summary}

The key findings are summarised in Table 2 following the three building blocks of science developed by De Vos et al. (2011).

Table 2

Key findings regarding knowledge of leadership, innovation and performance

\begin{tabular}{|c|c|}
\hline $\begin{array}{l}\text { Building blocks } \\
\text { of science }\end{array}$ & Findings \\
\hline Concepts & $\begin{array}{l}\text { The most common keywords are transformational leadership and organisational performance. Others } \\
\text { include organizational learning, knowledge management, organizational innovation, innovation, } \\
\text { dynamic capabilities and organizational innovativeness. }\end{array}$ \\
\hline \multirow{2}{*}{ Statements } & $\begin{array}{l}\text { The following is a synthesis of the definitions found in the articles: Leadership: Transformational } \\
\text { leaders focus on long term vision and inspire and motivate followers to buy into that vision. } \\
\text { Transactional leaders focus on individuals' self-interest. Innovation: Introduction of a new idea, } \\
\text { product, service or process. } \\
\text { Organizational performance: The ability to efficiently and effectively provide a service to the customer } \\
\text { while maintaining superior financial returns. }\end{array}$ \\
\hline & $\begin{array}{l}\text { Several hypotheses recurred in the articles: Transformational leadership style is positively and } \\
\text { significantly associated with innovation. Innovation is positively and significantly associated with } \\
\text { superior organizational performance. However, when both transformational and transactional } \\
\text { leadership were tested, the results reveal that transactional leadership style is better suited to } \\
\text { fostering organizational innovation, whereas transformational leadership style is better suited to } \\
\text { improving organizational performance. }\end{array}$ \\
\hline \multirow[t]{3}{*}{$\begin{array}{l}\text { Conceptual } \\
\text { framework }\end{array}$} & $\begin{array}{l}\text { The following typologies were common in the articles: Leadership: Leadership style is classified into } \\
\text { two most popular known styles of leadership, namely, the transformational and transactional } \\
\text { leadership styles. The studies investigated do not mention other types of leadership styles. Innovation: } \\
\text { None of the studies investigated bother to explore how innovation typologies will impact the nature of } \\
\text { the relationship between these three constructs. Performance: The two typologies of organizational } \\
\text { performance are operational performance and financial performance. The results reveal that } \\
\text { transformational leadership is positively associated with operational performance and in turn leads to } \\
\text { superior financial performance. However, only one study explored these typologies. None of the } \\
\text { studies explored these typologies using both transformational and transactional leadership styles. }\end{array}$ \\
\hline & $\begin{array}{l}\text { There was little distinction between the models presented: The synthesis of all the models developed } \\
\text { reveals that leadership style influences organizational innovation and in turn, innovative organisations } \\
\text { exhibit superior organizational performance compared to that of competitors. }\end{array}$ \\
\hline & $\begin{array}{l}\text { Although none of the studies explicitly mention the paradigm adopted, it can be deduced that } \\
\text { researchers adopted a positivist approach of the epistemology paradigm. }\end{array}$ \\
\hline
\end{tabular}

\section{Conclusion}

This paper reviewed seven peer-reviewed articles from EBSCOhost and ProQuest. The primary aim was to analyse articles that investigate the relationship between leadership style, innovation and organisational performance using three building blocks of science; concepts, statements and conceptual frameworks, as identified by De Vos et al. (2011).

In assessing the concepts (keywords) used, it can be concluded that the majority of scholars focus exclusively on transformational leadership style when investigating the relationship between three constructs. Interestingly enough, none of the articles use transactional leadership style as a concept. In the same vein, none of the articles use innovation typologies (incremental and radical), nor financial performance typologies such as return on investment (ROI) or return on assets (ROA). This suggests that very little attention, if any, is paid to the mediating effect of the nature of innovation, namely, incremental and radical, and to the objective measures of financial performance. However, a number of other mediating factors like organisational learning, knowledge management, and dynamic capabilities are considered. 
With regard to definitions, the analysis reveals that transformational leadership is the leadership style that is most frequently discussed. The common themes for transformational leadership style that emerge are: (1) influential (2) inspirational; (3) charismatic; (4) motivational; and (5) intellectually stimulating. In contrast, the common themes for transactional leadership style are: (1) exchange or bargain; and (2) individual self-interest. In the same vein, the common themes that emerge for innovation are: (1) new idea; (2) new product; or service or process. The central theme of organisational performance, on the other hand, is based on operational effectiveness and efficiency and the financial performance of the organisation.

Where hypotheses and truth statements were studied, the evidence shows that transformational leadership style plays a significant role in cultivating the culture of innovation in the organisation and, in turn, organisations that practise innovative behaviour generally exhibit superior organisational performance, relative to organisations that display less innovative behaviour. In contrast, more comprehensive analyses (studies that investigate both transformational and transactional leadership styles) of leadership styles reveal that transactional leadership style is better suited if the aim is to instil a culture of innovation, whereas transformational leadership style is mostly associated with the enhancement/improvement of organisational performance.

Typology was the first conceptual framework to be reported on. The assessment reveals a number of gaps in the literature. Firstly, despite the recent study conducted by Golla and Johnson (2013), which illustrates the importance of including transactional leadership style when investigating the relationship between leadership styles, innovation and performance, the majority of studies focus exclusively on transformational leadership style. Secondly, none of the studies investigate the mediating effect of the nature of innovation in the relationship between leadership, innovation and organisational performance. Thirdly, none of the studies use the objective measures of financial performance based on Generally Accepted Accounting Principles (GAAP) and market-based measures such as price/earnings $(\mathrm{P} / \mathrm{E})$ and Tobin's $\mathrm{Q}$.

Theories and models are based on the truth statements and the models previously developed. From studying the reported models, it can be concluded that both transformational and transactional leadership styles have a role to play in cultivating innovative behaviour in the organisation and improving organisations' performance. It is interesting to note that organisational learning plays a pivotal role in the relationship between leadership, innovation and organisational performance.

This article does not only contribute to the understanding of a theoretical link between these variables, but also has practical implications for those in managerial positions. The latter should be aware of the importance of clearly understanding the precise meaning of concepts when discussing relationships between them, and linked to this, the importance of using standardised measures when trying to demonstrate the link between these variables. Managers may also draw from this research that there is indeed a relationship between leadership styles, innovation and organisational performance, and that the appropriate leadership style is required to foster innovation and facilitate organisational performance. However, this is not a simple relationship. If the main aim is to improve organisational innovation, managers should consider adopting a transactional leadership style. If the main aim is to improve organisational performance, managers should consider adopting a transformational leadership style. If the main aim is to improve organisational performance using innovation as an enabler, managers should consider adopting both a transactional and a transformational leadership style. This is clearly a complex matter and managers are urged to proceed with caution, as available empirical research linking these variables is limited.

\section{$6 \quad$ Limitations and direction for future research}

The first limitation of this study is the sampling procedure. The study did not consider unpublished articles and dissertations. It has been a matter of speculation whether the results of this paper might have been different had dissertations been included as part of the search. Secondly, only 
EBSCOhost and ProQuest databases were searched. Although these databases are comprehensive, it is not known whether additional articles could have been found on other databases that met the specified search criteria. However, this inherent problem of reviews of the research literature is generally considered to be acceptable. Furthermore, very few articles (only seven) met the set criteria when all three variables were used (i.e. leadership, innovation and performance), indicating a gap in the literature.

The following future research on leadership, innovation and organisational performance is suggested: (1) the mediating effect of the nature of innovation (radical and incremental) on the relationship between leadership and organisational performance; and (2) the use of objective measures (i.e. measures based on Generally Accepted Accounting Principles and market-related measures calculated from annual financial data) of organisational performance, rather than the often subjective measures that are self-reported.

\section{References}

ADEGOKE, O., WALUMBWA, F.O. \& MYERS, A. 2012. Innovation strategy, human resource policy, and firms' revenue growth: The roles of environmental uncertainty and innovation performance. A Journal of Decision Sciences Institute, 43(2):273-301.

AL-HUSSEINI, S. \& ELBELTAGI, I. 2012. The impact of leadership style and knowledge sharing on innovation in Iraqi higher education institutions. Paper presented at the proceedings of the $4^{\text {th }}$ European Conference on Intellectual Capital, Arcada University of Applied Sciences, Helsinki, Finland.

BACHARACH, S.B. 1989. Organizational theories: Some criteria for evaluation. The Academy of Management Review, 14(4):496-515.

BASS, B.M. 1985. Leadership and performance beyond expectations. New York, NY: Free Press. BRYMAN, A. 2004. Social research method. Cape Town: Oxford University Press.

CAPECCHI, V. 1968. On the defination of typology and classification in sociology. Quality and Quantity, 2(1-2):9-30.

DE VOS, A.S., STRYDOM, H., FOUCHÉ, C.B. \& DELPORT, C.S.L. 2011. Research at grass roots: For the social sciences and human services profession ( $4^{\text {th }}$ ed.) Pretoria: Van Schaik.

DENYER, D. \& TRANFIELD, D. 2009. The Sage handbook of organizational research methods. London: Sage.

DURÁN-VÁZQUEZ, R., LORENZO-VALDÉS, A. \& MORENO-QUEZADA, G.E. 2012. Innovation and CSR impact on financial performance of selected companies in Mexico. Journal of Entrepreneurship,

Management and Innovation, 8(3):5-20.

FORSMAN, H. \& TEMEL, S. 2011. Innovation and business performance in small enterprises: An enterprise-level analysis. International Journal of Innovation Management, 15(3):641-665.

GARCÍA-MORALES, V.J., MATÍAS-RECHE, F. \& HURTADO-TORRES, N. 2008. Influence of transformational leadership on organizational innovation and performance depending on the level of organizational learning in the pharmaceutical sector. Journal of Organizational Change Management, 21(2): 188-212.

GARCÍA-MORALES, V.J., LLORÉNS-MONTES, FRANCISCO, J. \& VERDÚ-JOVER, A.J. 2008. The effects of transformational leadership on organizational performance through knowledge and innovation. British Journal of Management, 19(4):299-319.

GOLLA, E. \& JOHNSON, R. 2013. The relationship between transformational and transactional leadership styles and innovation commitment and output at commercial software companies. The Business Review Cambridge, 21(1):337-343.

GRANT, R. 2012. Contemporary strategy analysis: Text and cases. Malden, MA: Blackwell.

GREEN, B.N., JOHNSON, C.D. \& ADAMS, A. 2006. Writing narrative literature reviews for peer-reviewed journals: Secrets of the trade. Journal of Chiropractic Medicine, 5(3):102-117.

GUNDAY, G., ULUSOY, G., KILIC, K. \& ALPKAN, L. 2011. Effects of innovation types on firm performance. International Journal of Production, 133(2):662-676. 
HANDFIELD, R.B. \& MELNYK, S.A. 1998. The scientific theory-building process: A primer using the case of TQM. Journal of Operations Management, 16(4):321-339.

HORNBY, A.S. 2000. Oxford advanced learner's dictionary ( $6^{\text {th }}$ ed.) Oxford: Oxford University Press. HOWELL, J.M. \& AVOLIO, B.J. 1993. Transformational leadership, transactional leadership, locus of control, and support for innovation: Key predictors of consolidated-business-unit performance. Journal of Applied Psychology, 78(6):891-902

HU, H., GU, Q. \& CHEN, J. 2012. How and when does transformational leadership affect organizational creativity and innovation? Critical review and future directions. Nankai Business Review, 15(5):26-35.

KANDYBIN, A. \& KIHN, M. 2004. Raising your return on innovation investment. Available at: http://www.strategyand.pwc.com/media/uploads/Raising Your Return on Inno vation Investment.pdf [accessed 2015-01-10].

KANIKI, A.M. 2009. Research in practice: Applied method for the social sciences. Cape Town: UCT Press. KANNEBLEY, S., SEKKEL, J.V. \& ARAÚJO, B.C. 2008. Economic performance of Brazilian manufacturing firms: A counterfactual analysis of innovation impacts. Small Business Economics, 34(3): 339-353.

KERLINGER, F.N. \& LEE, H.B. 2000. Foundations of behavioral research. Forth Worth, TX: Harcourt College Publishers.

LÖÖF, H. \& HESHMATI, A. 2006. On the relationship between innovation and performance: A sensitivity analysis. Economics of Innovation and New Technology, 15(4-5):317-344.

MARTIN, M. 2012. Maximizing the return on business innovation expenditure in the case of emerging economies: Regional analysis. Paper presented at the International Conference on Management, Behavioral Sciences and Economics Issue, Penang, Malaysia.

MATZLER, K., KEPLER, J., DEUTINGER, N. \& HARMS, R. 2008. The relationship between transformational leadership, product innovation and performance in SMEs. Journal of Small Business and Entrepreneurship, 21(2):139-152.

MORRISON, J.M. 2003. A contribution to scientific knowledge. Available at: http://www.usb.ac.za/ Common/Pdfs/Working paper\%5B1\%5D.pdf [accessed 2015-01-10].

MOUTON, J. 1996. Understanding social research. Pretoria: Van Schaik.

NIGHTINGALE, A. 2009. A guide to systematic literature review. Surgery, 27(9):381-384.

NORUZY, A., DALFARD, V., AZHDARI, B., NAZARI-SHIRKOUHI, S. \& REZAZADEH, A. 2013.

Relations between transformational leadership, organizational learning, knowledge management, organizational innovation, and organizational performance: An empirical investigation of manufacturing firms. International Journal of Advanced Manufacturing Technology, 64(5-8):1073-1085.

NYBAKK, E. \& JENSSEN, J.I. 2012. Innovation strategy, working climate, and financial performance in traditional manufacturing firms: An empirical analysis. International Journal of Innovation Management, $16(2): 441-466$.

OMAR, N. \& LEITE, A. 1998. The learning process mediated by intelligent tutoring systems and conceptual learning. Paper presented at the International Conference on Engineering Education, Rio de Janeiro, Brazil.

OVERSTREET, R.E., HANNA.J.B., BYRD, T.A., CEGIELSKI, C.G. \& HAZEN, B.T. 2013. Leadership style and organizational innovativeness drive motor carriers toward sustained performance. The International Journal of Logistics Management, 24(2):247-270.

REYNOLDS, P.D. 1971. A primer in theory construction. Indianapolis, IN: Bobbs-Merril.

ROBSON, L.S., CLARKE, J.A., CULLEN, K., BIELECKY, A., SEVERIN, C., BIGELOW, P. L., IRVIN, E., CULYER, A. \& MAHOOD, Q. 2007. The effectiveness of occupational health and safety management system interventions: A systematic review. Safety Science, 45(3):329-353.

SELBY, J.W. 2010. A quantitative study describing the impact of innovation-related investment and management performance on corporate financial returns. Walden University. Unpublished $\mathrm{PhD}$ thesis.

TIPU, S., RYAN, J. \& FANTAZY, K. 2012. Transformational leadership in Pakistan: An examination of the relationship of transformational leadership to organizational culture and innovation propensity. Journal of Management and Organization, 18(4):461-480. 
TRANFIELD, D., DENYER, D. \& SMART, P. 2003. Towards a methodology for developing evidenceinformed management knowledge by means of systematic review. British Journal of Management, 14(3): 207-222.

WHETTEN, D.A. 1989. What constitutes a theoretical contribution? The Academy of Management Review, 14(4):490-495.

WHITE, A. \& SCHMIDT, K. 2005. Systematic literature reviews. Contemporary Therapies in Medicine, 13: 54-60. 